This item was submitted to Loughborough's Research Repository by the author.

Items in Figshare are protected by copyright, with all rights reserved, unless otherwise indicated.

\title{
Why people dual screen political debates and why it matters for democratic engagement
}

\section{PLEASE CITE THE PUBLISHED VERSION}

https://doi.org/10.1080/08838151.2017.1309415

\section{PUBLISHER}

(C) Broadcast Education Association. Published by Taylor and Francis

\section{VERSION}

AM (Accepted Manuscript)

\section{PUBLISHER STATEMENT}

This work is made available according to the conditions of the Creative Commons Attribution-NonCommercialNoDerivatives 4.0 International (CC BY-NC-ND 4.0) licence. Full details of this licence are available at: https://creativecommons.org/licenses/by-nc-nd/4.0/

\section{LICENCE}

CC BY-NC-ND 4.0

\section{REPOSITORY RECORD}

Chadwick, Andrew, Ben O'Loughlin, and Cristian Vaccari. 2019. "Why People Dual Screen Political Debates and Why It Matters for Democratic Engagement". figshare. https://hdl.handle.net/2134/27034. 
Why People Dual Screen Political Debates and Why It Matters for Democratic Engagement

Andrew Chadwick, Ben O’Loughlin and Cristian Vaccari

\begin{abstract}
Dual screening during televised election debates is a new domain in which political elites and journalists seek to influence audience attitudes and behavior. But to what extent do non-elite dual screeners seek to influence others, particularly their social media followers, social media users in general, and even politicians and journalists? And how does this behavior affect short- and longerterm engagement with election campaigns? Using unique, event-based, panel survey data from the main 2015 UK general election debate (Wave 1=2,351; Wave 2=1,168) we reveal the conditions under which people experience agency, empowerment, and engagement now that social media have reconfigured broadcast political television.
\end{abstract}

\title{
Keywords
}

Dual Screening, Political Engagement, Agency, Influence, Television, Social Media, Political Debates

Journal of Broadcasting and Electronic Media, 61 (2), 2017.

Author's Accepted Manuscript, April 20, 2017, for UK Research Excellence Framework eligibility. Please read and cite the copyedited and typeset version of this article, which will be found here after publication: http://www.tandfonline.com/loi/hbem20

Andrew Chadwick is Professor of Political Communication in the Centre for Research in Communication and Culture and the Department of Social Sciences at Loughborough University. Ben O'Loughlin is Professor of International Relations and Co-Director of the New Political Communication Unit, Department of Politics and International Relations, Royal Holloway, University of London. Cristian Vaccari is Reader in Political Communication in the Centre for Research in Communication and Culture and the Department of Social Sciences at Loughborough University.

We thank the participants in the panel "How We Use the News Now: Media Consumption and Attention in the 21st Century" at the American Political Science Association Annual Meeting in Philadelphia, August 2016, for their comments and suggestions on an earlier version of this article. We also thank Leticia Bode, Shelley Boulianne, Joshua Darr, Scott Eldridge, Marco di Felice, Ralph Negrine, Kaarle Nordenstreng, Katja Valaskivi, Josh Tucker, and Augusto Valeriani. 
Digitally-mediated commentary now accompanies broadcast political media events of all kinds, reconfiguring Dayan and Katz’s classic (1992) model of media events. Building on our earlier research, we define this as dual screening and conceptualize it as "the bundle of practices that involve integrating, and switching across and between, live broadcast media and social media” (Vaccari et al, 2015: 1041). Previously we studied the 2014 EU election debates in the United Kingdom and found that active, "lean-forward” dual screening practices, such as commenting live on social media as a debate unfolds, and engaging with conversations via Twitter hashtags, have the strongest and most consistent positive associations with political engagement (Vaccari et al, 2015). In this current article we shift our focus to motivations and influence and their links with cognitive and behavioral engagement. We break new ground in two ways. First, we use uniquely suitable data to assess the significance of dual screeners' motivations to acquire information, share information and opinions, and influence others, including politicians and journalists. Second, we analyze the links between these motivations and individuals' short-term and longer-term engagement with an election campaign.

Our data for this article come from Britain’s live, televised 2015 general election debate, broadcast by national channel ITV on April 2, 2015. With 7.4 million viewers (a 33 percent evening audience share) this was the main television event of the campaign and the first debate in British history to feature all seven major and minor party leaders on one stage. We used large-scale Twitter data to identify a sample of individuals who dual screened the debate. We then ran our own customdesigned, two-wave panel survey on this sample and analyzed the responses using a series of multivariate statistical models ( $N=2,351$ for wave $1 ; 1,168$ for wave 2$)$.

Our research design avoids some of the limitations of existing work on dual screening. Not only does our approach get inside individuals’ live dual screening experiences, it also allows us to look outside the live moment and explore how these experiences may explain subsequent attitudes and behaviors, both online and offline. We were also able to examine the characteristics of large numbers of social media users and go beyond examining influence by small numbers of politicians 
and media professionals. And, in contrast with previous research, we were able to design a custom survey that explicitly tapped individuals' motivations to influence others, as well as their estimated success in doing so.

There is much at stake here for the future of democratic engagement. Weeks and colleagues end their recent study of online opinion leaders (2015: 9) by questioning whether "prosumer" behavior online contributes to "the democratic process at large.” While the concept of influence often has pejorative associations with elite manipulation and spin, the long tradition of research on opinion leadership stretching back to Katz and Lazarsfeld (1955) is more positive: if sufficiently diffused, influence-oriented behavior can produce democratic goods for the polity. If dual screening affords individuals the capacity and opportunity to influence others, including elites, and it boosts their behavioral and cognitive engagement, it may make a contribution to the democratic renewal of electoral politics.

\section{Understanding Why People Dual Screen Political Debates: Information, Sharing, Influence, and Engagement}

Dual-screening is potentially reshaping political agency and the effects might scale up to alter the structure of communication relating to a televised political debate and the broader election campaign. Debates are now characterized by competition, conflict, and partisanship but also interdependence among actors who attempt to steer the flow and meanings of debate-related news. Journalists and politicians have integrated social media into their working practices. Broadcasters commission social media sentiment analysis, real-time online polls, and present vox-pop tweets from the viewing public to provide a demotic presence in the studio and post-event "spin room.” However, the power of political staff and journalists is increasingly prone to disruption by social media user-audience networks (Anstead and O’Loughlin, 2015; Chadwick, 2011a, 2011b).

Event-based studies have shown that people use social media to acquire information and news about the campaign, share information and opinions with others, and to try to influence the 
interpretive framing of their online followers, journalists, and politicians (Chadwick, 2011a, 2011b; Freelon \& Karpf, 2015; Mascaro \& Goggins, 2015; Wohn and Na, 2011). People evaluate and factcheck television presenters and try to place marginalized issues on reporters' agendas. They create and circulate specific hashtags, send publicly accessible tweets to journalists and campaign elites, craft satirical posts in attempts to generate shareable memes and viral information cascades, and try to subvert official news framings through the use of culturally-resonant affect, counterpoint, satire, exaggeration, sarcasm, trolling, and fake accounts. This is, in effect, a much more widely distributed, social media-enabled set of behaviors than those identified in Lang and Lang's (2002) broadcast-era work on the role of television presenter commentary in shaping audience perceptions. Previous research on the links between motivations and political engagement is also relevant. Our approach here is rooted in the dialogical tradition, which posits that the complex array of motivations and practices involved in an act of public expression can come to reshape the beliefs and behavior of the addresser as well as the addressee (Bakhtin, 1981; for recent work of relevance see for example Pingree, 2007; Shah, 2016). There is strong evidence that people are motivated to use the internet to acquire further information about politics and that this, in turn, can lead to increased interpersonal discussion and political messaging via email (Shah et al, 2005). Since the rise of social media, attention has shifted to how individuals' motivations to express themselves in their online social networks can interact with news use and spur political engagement (Gil de Zúñiga et al, 2014). There is also evidence of a broader shift toward an "actualizing” style of citizenship nourished by self-expressive behavior (Bennett, Wells \& Freelon, 2011). Similarly, Vraga and colleagues (2015) found that issue-specific engagement using Facebook is associated with enhanced political efficacy and self-reported opinion leadership. Study of the motivations for dual screening, as opposed to social media use in general, is in its infancy. However, Gil de Zúñiga and colleagues (2015) found that information-seeking and the motivation to discuss politics with others were linked to dual screening for news as well as subsequent online engagement. 
The communicative context during and immediately after a televised debate is relatively fertile. These are long and complex events containing many policy statements and subtle behavioral cues, very few of which become salient in journalists' reports and audience reactions. When they do become salient, it makes a difference to individuals’ responses (Shah et al, 2015). Older studies of traditional (not dual-screened) viewing of US primary and presidential debates have shown that these events can affect individuals’ levels of information, attitudes to the candidates, engagement, efficacy, and even vote choice (see for example Benoit et al., 2003; McKinney and Warner, 2013). Good data are thin on the ground in the UK context because live party leaders' debates only began in 2010. However, in that year the Liberal Democrat leader Nick Clegg enjoyed a surge in his personal ratings after his appearance in the televised debates, when dual screeners introduced the hashtags \#iagreewithnick and \#nickcleggsfault (Chadwick, 2011a).

We should also examine the short-term “opportunity structure” (Chadwick, 2011b: 5-8) that now shapes engagement immediately after a broadcast event. Getting involved soon after a debate offers individuals the opportunity to influence others' perceptions of the debate itself. Actions can be timed for when politicians, campaign workers, professional journalists, and political activists are involved in a struggle to define the candidates' key strengths and weaknesses. However, post-debate actions like contributing to post-debate donation surges, voting in online petitions and polls, or following a party leader on Twitter are not narrowly instrumental; they are also indirect information signals designed to influence broader perceptions. These forms of engagement leave visible traces that can be read by others as signs of support for a candidate or cause (Chadwick, 2013: 124-5).

This is all the more important because substantial proportions of social network users are relatively uninterested in politics and/or undecided in their political preferences. These individuals might gain campaign engagement benefits from being serendipitously exposed to dual-screened content about a televised political debate. ${ }^{1}$ At the same time, more politically-interested dual

\footnotetext{
${ }^{1}$ Data from the 2015 British Election Study (BES) post-election survey show that that 41.8 percent of the 52.8 percent of total survey respondents who reported using either Facebook or Twitter were "not very interested" or "not at all
} 
screeners may learn more about the 'rules of the game’ of politics (Holton et al., 2015: 2540) and how to more successfully exercise influence over others.

In light of these themes, we based our study on four research questions. The first two probed individuals' motivations to dual screen the ITV debate and their perceptions of the outcome of their behaviors. The third and fourth probed the subsequent implications of dual screening for short-term and longer-term forms of engagement with the election.

- RQ1. What kinds of motivations lead Twitter users to dual screen political debates and what kinds of social and political characteristics are associated with these motivations?

- RQ2. How do individuals perceive the influence-related outcomes of their dual screening experiences?

- RQ3. Are there any relationships between dual screening behaviors and engagement in the important post-debate opportunity structure immediately after a debate?

- RQ4. Are there any relationships between dual screening a debate and engagement that persists until after election day?

\section{Research Design and Method}

By 2015, 27 percent of Britain’s population reported checking their social media feeds while watching television. ${ }^{2}$ By 2013, 22 percent of the British population used Twitter, making it the second most popular social networking site in the United Kingdom, after Facebook. And, by 2014, 60 percent of UK Twitter users reported using the service while watching television (Vaccari et al, 2015: 1047).

The unique nature of dual screening requires research designs that integrate the digitallymediated, episodic, personalized, and event-based forms of political engagement that are now important for politics. We deployed two custom-built surveys: one immediately after the event and 
a second the day after election day. While we acknowledge that self-reports are no substitute for directly-observed behavior, it is only from surveys that we can learn about how large numbers of individuals actually experience dual screening and what they tend to do outside of the live, dual screening moment.

\section{The April 2, 2015 ITV \#Leadersdebate}

Professional media covered the ITV leaders' debate intensely. The two-hour broadcast attracted 7.4 million viewers—a large (33\%) audience share for the evening. ${ }^{3}$ We defined our population as those Twitter users who posted at least one tweet about the debate during a six hour period— the two hours before the debate, during the debate itself, and the two hours immediately after the debate had ended. We chose this time frame in order to tap both the build-up to the debate and the initial discussions on its outcome, when Twitter activity spikes and interpretive frames are up for grabs (Chadwick, 2011a). To identify our population, we mined Twitter's Streaming API ${ }^{4}$ from 6pm until midnight on April 2 for tweets containing “\#leadersdebate,” which ITV had earlier announced as the event's official hashtag. This was a Twitter trending topic in Britain during the entire day and the top trending topic in Britain and worldwide during the debate. In total, we collected 516,484 tweets (including retweets) posted by 164,262 unique users. From this population we randomly selected a sample of 32,854 users. We then used several Twitter accounts—created specifically for this project and clearly indicating our institutional affiliation and research — to invite these users to take our Wave 1 survey. The Wave 1 survey invitations were sent between April 3 and April 6, 2015; responses were collected until April 12, 2015. ${ }^{5}$

In total, 2,351 users completed our Wave 1 survey—7.2 percent of the 32,854 Twitter users

\footnotetext{
2 See http://www.digitalnewsreport.org/ (accessed March 10, 2016).

${ }^{3}$ See http://www.theguardian.com/politics/2015/apr/03/7m-people-watched-leaders-debate-itv-seven-etchingham (accessed March 10, 2016).

4 Twitter's Streaming API allows researchers to retrieve public Twitter messages in real time, together with relevant metadata. See https://dev.twitter.com/streaming/overview (accessed November 28, 2016).
} 
to whom we sent invitations. Respondents took, on average, about 23 minutes to complete the survey. Of these 2,351 respondents, 1,832 provided their Twitter name and/or email address and agreed to be contacted by us in future. This enabled us to survey these 1,832 respondents again immediately after election day, for our Wave 2 survey. Wave 2 ran from the day immediately after the general election (Friday, May 8) to June 16, 2015, and generated 1,168 responses. These 1,168 respondents thus constitute our two-wave panel for exploring longer-term engagement with the campaign. Despite our unorthodox method, the panel had a healthy retention rate of 64 percent. Our online appendix ${ }^{6}$ provides extensive information on the characteristics of our respondents and the survey questions we used for our analysis below, as well as evidence from a separate benchmarking survey we conducted on a nationally-representative sample of UK internet users. The benchmarking data show that our sample is remarkably similar to our target population and our data are wellsuited to our research questions. As we shall see below, our cross-sectional data revealed significant associations between motivations, perceived outcomes, and short-term engagement. Our panel data yield insights on the enduring influence of dual screening. Most studies of social media and engagement have relied solely on cross-sectional data. Panel designs tend to find fewer and weaker associations between media and engagement (Boulianne, 2015), but generate robust estimates of stability and change because they allow us to control for the values of the dependent variables measured at an earlier point in time.

\section{Results}

We adopted a multi-phase approach, in which the dependent variables differ according to the research question.

\footnotetext{
${ }^{5}$ The surveys were hosted at Qualtrics. For more detail on the survey and question wording please consult our online appendix at http://files.andrewchadwick.com/Chadwick-OLoughlin-Vaccari-JoBEM-2017-Online-Appendix.pdf ${ }^{6}$ Available at http://files.andrewchadwick.com/Chadwick-OLoughlin-Vaccari-JoBEM-2017-Online-Appendix.pdf.
} 
RQ1: Motivations for Dual Screening the Debate: Information, Sharing, Influence, and their Attitudinal and Behavioral Correlates

To identify motivations for dual-screening the debate, our survey contained three pairs of questions about the importance of acquiring new information, sharing information and opinions with others, and attempting to influence other social media users and professional media. Respondents attributed greater importance to acquiring information (mean $=4.00, \mathrm{SD}=1.55)$ and sharing information and opinions (mean $=3.98, \mathrm{SD}=1.72$ ) than influencing other social media users and professional media (mean $=2.55, \mathrm{SD}=2.04$; all variables range $0-6)$. Table 1 shows how individuals' sociodemographic characteristics, political characteristics, and social media use predict these motivations.

- Table 1 here -

The data reveal interesting differences in the variables that predict the three sets of motivations we investigated. While women were significantly more likely to dual screen to acquire information, men were significantly more likely to seek influence. Those who scored low on political efficacy and who did not feel they were learning enough from the campaign to make an informed choice were significantly more likely to dual screen to acquire information, as were those who reported greater levels of political news use. Those who identified with a political party and reported higher levels of political efficacy were significantly more likely to aim to share information and opinions while dual screening, while those who sought to influence others had significantly higher levels of interest in politics.

Levels of attention to the campaign were positively and significantly associated with the motivation to acquire information and to share information and opinion. Online political engagement was positively and significantly associated with all three motivations, while offline political engagement was positively and significantly associated with the motivation to share content and influence others. Frequency of access to Twitter was positively and significantly associated with the motivation to acquire information and share information and opinions, while 
frequency of access to other social media was positively and significantly associated with the desire to influence others.

\section{RQ2: Perceived Influence-Related and Cognitive Outcomes of Dual Screening}

In Table 2, we show how dual screening shaped individuals' sense of their own agency to influence others and the feeling they had learned information that was valuable for their vote decision. We asked respondents to state if their comments on the debate on Twitter influenced four distinct groups we chose for their rank order in terms of probable difficulty: their own Twitter followers, Twitter users in general, journalists, and politicians. In the aggregate, our respondents were modest in assessing their ability to influence others: 55.6 percent claimed to have at least “a little” influence on their own followers, 38 percent on Twitter users in general, 11.7 percent on journalists, and 11.2 percent on politicians. We also asked respondents how much they believed discussing the debate on Twitter helped them in their voting decision. A plurality of respondents (42.8\%) claimed it was “somewhat helpful”; 12.9 percent deemed it "very helpful.”

Together with independent variables relating to social and political characteristics, Table 2 also includes variables measuring particular dual screening behaviors and Twitter affordances that we found in our previous research to be important for shaping political engagement (Vaccari et al., 2015). We included the following: whether an individual had watched the debate live on television, tuned in to the debate after having read about it on social media, or read about or commented on the debate on social media. The variables that tap specific Twitter affordances for dual screening were: reading tweets about the debate in one's timeline, encountering information via hashtags, being sent an @message or a direct message about the debate, and searching for comments on the debates using the Twitter search bar. Finally, we added the motivational dependent variables from our first model—acquiring information, sharing information and opinions, and seeking influence-as independent variables. This allowed us to gauge whether these motivations were in fact satisfied. 
Table 2 shows that all three motivations for dual screening the debate-acquiring information, sharing information and opinions, and influencing others-positively and significantly correlate with the view that dual screening assisted with deciding how to vote. The motivation to dual screen to influence others was positively and significantly associated with respondents' perceptions that they had influenced all of the groups we asked about: their Twitter followers, Twitter users in general, journalists, and politicians. The desire to share information and opinions was positively and significantly associated with respondents' perceptions of having influenced their immediate Twitter network and the broader network of Twitter users, but not journalists and politicians. Those who mostly valued acquiring information were significantly more likely to feel they had influenced Twitter users in general.

Consistent with our findings on motivations from Table 1, men were significantly more likely than women to perceive that their comments on Twitter were influential on their followers, but women were significantly more likely to report that dual screening was useful for their voting decision.

Table 2 also unearths intriguing relationships between the perceived outcomes of dual screening and important political characteristics. Those with higher levels of political news use were significantly more likely to report their discussions on Twitter had an influence on journalists. Respondents who were more politically-engaged offline were significantly more likely to perceive that their discussions influenced their followers and Twitter users in general, as were respondents with higher levels of online engagement, though these latter individuals also felt significantly more influential on journalists. By contrast, political interest and efficacy were negatively and significantly associated with finding the discussions useful for deciding how to vote, while political interest was also negatively and significantly associated with perceived influence over Twitter users.

Perceptions of influence and assistance with voting decision were also associated with specific dual screening practices and Twitter affordances. Our measure of serendipitous exposure- 
tuning in to the television debate after reading about it on social media—was positively and significantly correlated with acquiring information that helped with deciding how to vote and with perceived influence on Twitter users, journalists, and politicians. Similarly, those who followed debate hashtags were significantly more likely to see themselves as influential on Twitter users and on politicians. Engaging with hashtags and seeing debate-related posts on one's timeline were also positively and significantly associated with finding dual screening useful in deciding how to vote. Respondents who commented on the debate on social media and who received debate-related tweets mentioning their username or direct messages also reported significantly higher levels of influence on their followers and Twitter users in general.

\section{RQ3: Dual Screening and Immediate Post-Debate Engagement}

Our third research question investigates relationships between dual screening behaviors and engagement in the immediate aftermath of the debate. The dependent variable measuring postdebate engagement is an index comprising eight different activities, including, for example, signing an online petition related to the debate, donating money, voting in an online poll related to the debate, or signing up to volunteer for a party or cause. These speak to our discussion about shortterm, post-debate engagement as both direct intervention in politics and indirect information signaling designed to influence the perceptions of others. The average value of the index of postdebate engagement, which ranges from $0-8$, was $1.38(\mathrm{SD}=1.45)$. Because the dependent variable is a count, we employed Poisson regression with robust standard errors. ${ }^{7}$ As with Table 2, we build on our previous model by adding the dependent variables from the previous table-perceived influence on others and assistance with voting decision—as independent variables. ${ }^{8}$

- Table 3 here -

\footnotetext{
${ }^{7}$ As the ratio between the model's Chi square coefficient and the number of degrees of freedom is lower than 1 (.969), we can conclude that overdispersion does not affect our data and that our model overestimates the standard errors.

${ }^{8}$ Here we recoded perceived influence on others as a combined measure. See the online appendix at http://files.andrewchadwick.com/Chadwick-OLoughlin-Vaccari-JoBEM-2017-Online-Appendix.pdf
} 
As Table 3, column 1 shows, those identifying with a party and those more engaged online and offline reported participating in a significantly higher number of post-debate activities. In addition, the perception that dual screening assisted with one's voting decision and the perception of having influenced others were positive and significant predictors of post-debate engagement. Interestingly, the motivation to dual screen to acquire information was positively and significantly associated with post-debate engagement, but the motivations to share content and to influence others were not.

Specific dual-screening behaviors and Twitter affordances also matter for short-term postdebate engagement. In a finding that echoes Vaccari et al (2015), relatively active behaviors such as commenting on the debate on social media, encountering hashtag-centered discussions and searching for information using the Twitter search bar are positive and significant predictors of post-debate engagement. Even relatively passive social media behaviors such as reading about the debates on social media and receiving mentions and direct messages about the debate were positively and significantly associated with post-debate engagement.

\section{RQ4: Dual Screening and Longer-Term Engagement}

Our final research question concerned the relationship between dual screening the debate and any engagement that persists until after election day. Here we use our panel data, which we gathered in the post-election survey. In both waves, the majority of our respondents said they were following the campaign "very closely": 59 percent in Wave 1; 70 percent in Wave 2. In Wave 1, 72 percent reported they were learning enough to make an informed choice; in Wave 2, 81 percent reported this.

As columns 2 and 3 of Table 3 reveal, we found important relationships between dual screening and cognitive engagement during the remainder of the campaign. Respondents who commented via social media on the debate were more likely to increase both their attention to the campaign and their perceptions that they had learned enough to make an informed choice. These 
relationships are statistically significant even after controlling for all the variables shown in Table 3-including the value of the dependent variables recorded at Wave 1.

\section{Discussion}

How do we make sense of these results? In this section we show how they shed light on the motivations for dual screening and how these motivations relate to individuals' social and political characteristics (RQ1); how dual screening assists with vote choice and contributes to the perception of influence over others (RQ2); how it shapes engagement in the immediate post-debate opportunity structure (RQ3); and how it provides longer-term cognitive benefits (RQ4).

With regard to $R Q 1$, dual screening is seen by many respondents as an opportunity to fulfill their civic duties by plugging information gaps left by routine campaign news. Individuals who felt they had not learned enough from the campaign and who had a weaker sense of their own political efficacy were particularly keen to dual screen to acquire information. Dual screening's role as a civic ritual is confirmed by our finding that even those who were paying close attention to the campaign and who reported higher levels of news usage still wanted to dual screen to acquire and share information. These people already had a relatively rich diet of political information but they dual screened to further enrich it. This civic ritual role was also highlighted by the positive associations between respondents’ political participation and their motivations for dual screening. Dual screening to spread information and influence others is a new and important part of the political behavior of those who already have the broadest engagement repertoires, both online and offline.

However, dual screening to influence others is a strident act of citizenship, and more likely to lead to active agency. This may contribute to explaining the gender agency divide we found, with women more likely to be motivated to acquire information and men more likely to be interested in influencing others. This surprising finding raises important questions, which we discuss in our Conclusion. 
Our results show that dual screening the debate had important positive cognitive engagement outcomes, even after controlling for a wide range of other variables (RQ2). Those who were motivated to influence journalists and politicians clearly found dual screening useful for doing so. Those who mostly valued sharing information and opinions could see that their behavior might have had some influence on their immediate Twitter network and the broader network of Twitter users, but not on journalists and politicians. Thus, there is an important divide here. On one side are individuals who are highly motivated to achieve interpersonal influence, and who wish to take opinion leadership to new heights by orienting their behavior toward influencing not only their own Twitter followers but also professional media and politicians. This behavior partly reverses the direction of flow in traditional models of opinion leadership: it involves individuals acting back on elites rather than simply re-transmitting elites’ messages. On the other side of the divide, however, sit those who follow a more conventional model of opinion leadership that involves sharing information and opinion, and influencing their own followers and Twitter users in general, but not media and political elites. We revisit the significance of this divide in our Conclusion.

The positive association we found between higher levels of news use and the perception of having influenced journalists while dual screening augments this point about information flows. As highlighted in our conceptual discussion, qualitative studies of the integration of social media behavior with broadcast content have found that individuals use social media to introduce information that journalists and political actors find useful in their strategies to bolster or contest an emerging interpretation (Chadwick, 2011a; 2011b). The findings from this study refine this point: individuals who regularly engage with news are more likely to use social media to plug in to newsmaking assemblages and try to influence journalists during a televised debate. This suggests that news consumption in general is an important civic driver in the dual screening environment.

It would be a mistake, however, to simply state that dual screening reinforces existing engagement inequalities. After all, our results show that political interest and efficacy were negatively associated with finding the discussions useful for deciding how to vote, while political 
interest was also negatively associated with perceived influence over Twitter users in general. What this means is that respondents who were less politically efficacious and less interested in politics received relatively greater cognitive and influence benefits from dual screening the debate. They were more likely to see their behavior as influencing Twitter users in general and to see dual screening as having helped with their vote decision. Although this finding should be treated with some caution because our survey respondents as a whole were skewed toward the politically interested, ${ }^{9}$ it nonetheless reveals how dual screening can boost the capacity of people who are less engaged in politics but drawn into social media discussion of high-stakes, broadcast political events. In addition, serendipitous exposure to the debate via dual screening provided important cognitive and influence benefits. People who were not planning to watch the debate, but who ended up tuning in on television after reading about it online, derived the greatest cognitive and influence rewards. They reported influencing Twitter users in general, journalists, and politicians, and acquiring information that helped with deciding how to vote. We consider this finding related to influence benefits particularly surprising and powerful. Not only does it generally reinforce the finding that dual screening can boost the capacity of the less engaged, it also reveals how a specific bundle of behaviors that are such an important part of the dual screening experience-switching to dual screen using social media and television after reading about an event on social media—can empower individuals to exercise opinion leadership. Hashtags also play a role here. They appear to enable individuals to explore content and interact with users to which they may not normally be exposed. This may explain why people who engaged with hashtags also experienced influence and cognitive benefits.

Our results also indicate that dual screening spurs those who are already politically-engaged to try to extend their influence by engaging in the immediate post-debate opportunity structure (RQ3). Dual screening now appears to be well integrated with existing online and offline

\footnotetext{
${ }^{9}$ See our online appendix at http://files.andrewchadwick.com/Chadwick-OLoughlin-Vaccari-JoBEM-2017-OnlineAppendix.pdf.
} 
engagement repertoires and partisan identifications. However, it is not simply that dual screening provides these opportunities for the highly engaged. As the results show, those who were more likely to be open to influence (because they sought information rather than sought to share information and influence others) also reported higher levels of post-debate engagement. We see this as a positive outcome for those with a comparatively weaker sense of agency. Influence-seekers are not the only ones who become politically active after dual screening a debate; informationseekers do, too.

Finally, commenting on a debate while dual screening plays an important role in enhancing long-term cognitive engagement with a campaign (RQ4). This was the case even among those who were already attentive to, and learning from, the campaign. Indeed, while we have taken care to address the complexity of the relationships between dual screening motivations, perceived outcomes, and engagement, taken overall, the practice of commenting on the debate via social media emerges as one of the most important variables in our analysis. It positively predicts perceived influence on one’s Twitter followers and Twitter users in general (RQ2), immediate postdebate engagement (RQ3), and longer-term attentiveness and learning (RQ4).

\section{Conclusion}

We found significant evidence that dual screening has some positive influences on individuals' sense of political agency and both their short- and longer-term engagement with an election campaign. These influences derive from the complex, reconfigured context of today's televised political debates.

Our analysis also sheds light on how power might come to be exercised in the post-debate opportunity structure. Dual screening enables individuals to continue to assert their agency in the important immediate post-debate period, and signal their support for a candidate or party to others. Indeed, our finding that party identification is positively linked with post-debate engagement suggests that further research might explore the role parties play in structuring how citizens express 
their support during the period when frame dominance is being determined.

Our study provides further evidence that the hybrid mix of television and social media can lead to positive outcomes for democratic engagement beyond those who are political “junkies” (cf. de Zúñiga et al, 2015; Vaccari et al, 2015). Dual screening is not simply a "weapon of the strong.” While we caution that our sample is skewed toward the politically-interested, we still found evidence that those who were less politically efficacious and less politically-interested were more likely to receive cognitive and influence-related benefits from dual screening. For these individuals, dual screening appears to be useful for learning about the election and gaining influence over Twitter users beyond their own followers, though this influence does not extend to journalists and politicians. Similarly, those who sought to acquire information from the debate actually reported higher levels of post-debate engagement. Dual screening appears to have nudged these informationseekers to get involved immediately after the debate. Serendipity plays a role here, too. The greatest cognitive and influence rewards were experienced by those who did not actually plan to watch the televised debate but who ended up watching after reading about it on social media. This is an intriguing reversal of an earlier process identified by Bimber and Davis (2003), who found that serendipitous exposure to a candidate via television prompted individuals to search for the candidate online and get more involved in a campaign.

Social media affordances are important in explaining the difference dual screening can make to political television. Using social media to read about and to comment on the debate, encountering Twitter hashtags, searching Twitter, and being exposed to debate-related messages posted by others mentioning one's username were all associated with higher levels of immediate post-debate engagement. Those who followed discussions on hashtags reported that their comments had influenced Twitter users in general and politicians; they also reported that such conversations assisted with vote choice. And, as our Wave 2 data revealed, social media use during dual screening also had positive longer-term influences on cognitive engagement with the campaign. Even after controlling for a wide range of other variables and the responses of individuals at Wave 1 , 
commenting on the debate on social media was positively associated with increased attention to the campaign and learning enough to make an informed vote choice. Social media, particularly Twitter, are essential ingredients for political engagement during and after mediated political events. They make it more likely that people will feel empowered, become politically engaged immediately after the debate, acquire information that is useful in forming political judgments, and maintain higher levels of cognitive engagement during the rest of the campaign.

Taken together, these findings are important confirmation of the additional benefits of increased agency, empowerment, and engagement that people experience now that social media have reconfigured previously unidirectional, broadcast-only political television.

At the same time, our argument is tempered by two important caveats. The first is our finding that there is a motivations and influence divide. There are highly motivated influencers who strategically and, in their own assessments, successfully influence their own Twitter followers, Twitter users in general, journalists, and politicians. As we mentioned in our theoretical discussion these people reverse the top-down direction of flow of Katz and Lazarsfeld's (1955) classic twostep flow model of opinion leadership, further complicating what "personal influence” actually means in today's media systems (Dubois and Gaffney, 2014). On the other side of this divide are those who prioritize sharing information and opinions and only see their influence spreading as far as their own Twitter followers and Twitter users in general. Of course, influence over Twitter users beyond one's immediate followers should not be dismissed lightly: it is an agentic act. However, because it is not aimed at elites, it conforms more closely to the traditional top-down model of opinion leadership.

The second caveat is our unexpected identification of what we tentatively label the gender agency divide. In the case of the 2015 ITV leaders' debate, women dual screeners were more likely to be information-seekers and report that dual screening had assisted with their voting decisions. Men were more likely to be influence-seekers and report that they had achieved influence over others. Does dual screening political debates therefore reinforce patterns of gender inequality 
unearthed by previous research on political engagement (see for example Burns, Schlozman and Verba, 2001)? Is this finding unique to our data or related in some way to a complex array of other gender-related variables that we did not include in our design? It could be that under certain conditions women are less motivated than men to engage in the active commenting practices that are important for achieving influence. Recent evidence from Bode’s (2016, 12-13) study of online engagement in the US suggests there are few gender differences but there is a divide based on the visibility of an engagement behavior: men are more likely to post about politics; women are more likely to comment on others’ postings and disconnect from others for political reasons. However, Bode did not study dual screening, and in any case our findings suggest that men's and women's motivations and perceived outcomes can differ markedly, and these might condition their engagement behaviors. Of course, it could be that men have unrealistic expectations and/or inflated views of their own agency. Either way, the gender agency divide is an important avenue for future research.

Indeed, much further research is needed in this area. One important factor is how the content of people’s social media posts interacts with their self-reported behaviors. Future research must aim to identify the achievement of influence, not just reports of influence, as we did here. This is a formidable challenge, but one that will continue to center dual screening research on essential questions of agency and democracy. 


\section{References}

Anstead, N., \& O'Loughlin, B. (2015). Social media analysis and public opinion: The 2010 UK general election. Journal of Computer-Mediated Communication, 20(2), 204-220.

Bakhtin, M. M. 1981. The dialogic imagination. M. Holquist, ed. Austin: University of Texas Press [Translated by C. Emerson, M. Holquist.].

Benoit, W. L., Hansen, G. J., \& Verser, R. M. (2003). A meta-analysis of the effects of viewing U.S. presidential debates. Communication Monographs, 70(4), 335-350.

Bennett, W. L., Wells, C. \& Freelon, D. (2011) Communicating civic engagement: Contrasting models of citizenship in the youth web sphere. Journal of Communication 61(5), 835856.

Bimber, B. \& Davis, R. (2003). Campaigning online: the internet in US elections. New York: Oxford University Press.

Bode, L. (2016). Closing the gap: Gender parity in political engagement on social media. Information, Communication, and Society. Online First. DOI: 10.1080/1369118X.2016.1202302.

Burns, N., Schlozman, K. L., \& Verba, S. (2001). The private roots of public action: Gender, equality, and political participation. Cambridge, MA: Harvard University Press.

Chadwick, A. (2011a). Britain’s first live televised party leaders’ debate: From the news cycle to the political information cycle. Parliamentary Affairs 64(1), 24-44.

Chadwick, A. (2011b). The political information cycle in a hybrid news system: the British prime minister and the “bullygate” affair.' International Journal of Press/Politics 16(1), 3-29.

Chadwick, A. (2013) The hybrid media system: Politics and power. New York: Oxford University Press.

Dayan, D., \& Katz, E. (1992). Media events: The live broadcasting of history. Cambridge, MA: Harvard University Press. 
Dubois, E. and Gaffney, D. (2014). The multiple facets of influence: Identifying political influentials and opinion leaders on Twitter. American Behavioral Scientist, 58(10), 1260-1277.

Freelon, D., \& Karpf, D. (2015). Of big birds and bayonets: Hybrid Twitter interactivity in the 2012 presidential debates. Information, Communication and Society, 18(4), 390-406.

Gil de Zúñiga, H., Garcia-Perdomo, V. \& McGregor, S. C. (2015). What is second screening? Exploring motivations of second screen use and its effect on online political participation. Journal of Communication, 65(5), 793-815.

Gil de Zúñiga, H., Molyneux, L., \& Zheng, P. (2014). Social media, political expression, and political participation: Panel analysis of lagged and concurrent relationships. Journal of Communication 64(4), 612-634.

Holton, A. E., Coddington, M., Lewis, S. C., \& Gil de Zúñiga, H. (2015). Reciprocity and the news: The role of personal and social media reciprocity in news creation and consumption. International Journal of Communication, 9, 2526-2547.

Katz, E. and Lazarsfeld, P. F. 1955. Personal influence: The part played by people in the flow of mass communications. Glencoe, Ill: Free Press.

Lang, K. and Lang, G. (2002). Television and politics. Second Edition. New Brunswick, NJ: Transaction.

Mascaro, C. M. \& Goggins, S. P. (2015). Technologically mediated political discourse during a nationally televised GOP primary debate. Journal of Information Technology \& Politics, 12 (3), 252-269.

McKinney, M. S. \& Warner, B. R. (2013). Do presidential debates matter? Examining a decade of campaign debate effects. Argumentation and Advocacy, 49(1), 238-258.

Pingree, R. J. (2007). How messages affect their senders: A more general model of message effects and implications for deliberation. Communication Theory, 17(4), 349-461.

Shah, D. V. (2016). Conversation is the soul of democracy: Expression effects, communication mediation, and digital media. Communication and the Public, 1(1), 12-18. 
Shah, D. V., Cho, J., Eveland, W. P. \& Kwak, N. (2005). Information and expression in a digital age: Modeling internet effects on civic participation. Communication Research, 32(5), 531565.

Shah, D. V., Hanna, A., Bucy, E. P., Wells, C. \& Quevedo, V. (2015). The power of television images in a social media age: Linking biobehavioral and computational approaches via the second screen. Annals of the American Academy of Political and Social Sciences 659(1), 225244.

Vaccari, C., Chadwick, A. and O’Loughlin, B. (2015). Dual screening the political: Media events, social media, and citizen engagement. Journal of Communication, 65(6), 1041-1061.

Vraga, E. K., Anderson, A. A., Kotcher, J. E., \& Maibach, E. W. (2015). Issue-specific engagement: How Facebook contributes to opinion leadership and efficacy on energy and climate issues. Journal of Information Technology \& Politics 12(2), 200-218.

Weeks, B. E., Ardèvol-Abreu, A., \& Gil de Zúñiga, H. (2015). Online influence? Social media use, opinion leadership, and political persuasion. International Journal of Public Opinion Research, 1-26. Online First. DOI: 10.1093/ijpor/edv050. 
Table 1: Factors Predicting Motivations for Dual Screening the Debate (Ordinal Logistic Regression, Wave 1 Survey)

\begin{tabular}{lccc}
\hline & Information & Sharing & Influencing \\
\hline Gender (male) & $-.480^{* * *}$ & -.127 & $.225^{* *}$ \\
Age (years) & $-.023^{* * *}$ & $-.020^{* * *}$ & $-.009^{* *}$ \\
Education (age of completion) & $-.114^{* *}$ & $-.136^{* * *}$ & -.071 \\
Income (monthly household before tax) & $-.018^{* *}$ & $-.018^{*}$ & -.013 \\
Interest in politics & .097 & .112 & $.195^{*}$ \\
Internal political efficacy & $-.036^{*}$ & $.041^{*}$ & .031 \\
Identifying with a party & .254 & $.309^{*}$ & .225 \\
Level of attention to the campaign & $.235^{* *}$ & $.342^{* * *}$ & .165 \\
Learning enough from the campaign & $-.188^{*}$ & -.031 & .078 \\
Index of political news use & $.030^{* *}$ & .000 & -.001 \\
Index of offline political engagement & .006 & $.030^{* * *}$ & $.038^{* * *}$ \\
Index of online political engagement & $.008^{* * *}$ & $.008^{* * *}$ & $.008^{* * *}$ \\
Frequency of access to Twitter & $.206^{* *}$ & $.261^{* * *}$ & .084 \\
Frequency of access to other social media & .012 & .046 & $.095^{*}$ \\
& & & \\
$N$ & 1973 & 1962 & 1924 \\
Cox and Snell $R^{2}$ & .102 & .177 & .186 \\
-2 Log-likelihood & 6733.56 & 6640.52 & 6817.46 \\
\hline
\end{tabular}

Note: cell entries are unstandardized slope coefficients for the independent variables. ${ }^{* * *} \mathrm{p} \leq .001$ $* * \mathrm{p} \leq .01 * \mathrm{p} \leq .05$. 
Table 2: Factors Predicting Perceived Influence on Others as a Result of Dual Screening (Logistic Regression, Wave 1 Survey) and Usefulness of Dual Screening in Assisting with Voting Decision (Ordinal Logistic Regression, Wave 1 Survey)

\begin{tabular}{|c|c|c|c|c|c|}
\hline & $\begin{array}{l}\text { Influence on } \\
\text { one's followers }\end{array}$ & $\begin{array}{l}\text { Influence on } \\
\text { Twitter users }\end{array}$ & $\begin{array}{c}\text { Influence on } \\
\text { journalists }\end{array}$ & $\begin{array}{c}\text { Influence on } \\
\text { politicians }\end{array}$ & $\begin{array}{l}\text { Assistance with } \\
\text { voting decision }\end{array}$ \\
\hline Gender (male) & $.335^{* *}$ & .116 & .082 & -.183 & $-.281 * *$ \\
\hline Age (years) & -.005 & .006 & -.002 & -.008 & $-.012 * * *$ \\
\hline Education (age of completion) & .032 & -.057 & .061 & -.102 & -.097 \\
\hline Income (monthly household before tax) & .004 & -.004 & .009 & .001 & -.008 \\
\hline Interest in politics & -.146 & $-.318^{*}$ & -.110 & -.136 & $-.318 * *$ \\
\hline Internal political efficacy & .029 & .030 & .024 & .006 & $-.048 *$ \\
\hline Identifying with a party & .065 & -.154 & -.553 & -.121 & -.003 \\
\hline Attention to the campaign & .054 & .250 & .165 & -.179 & -.028 \\
\hline Learning enough from the campaign & .001 & -.167 & .142 & .398 & .142 \\
\hline Index of political news use & .000 & .000 & $.060 * *$ & .031 & .016 \\
\hline Index of offline political engagement & $.012 *$ & $.013 *$ & -.007 & .014 & .003 \\
\hline Index of online political engagement & $.020 * * *$ & $.010^{* *}$ & $.010^{*}$ & .009 & .006 \\
\hline Frequency of access to Twitter & .120 & .042 & -.083 & -.004 & $.284 * * *$ \\
\hline Frequency of access to other social media & -.042 & -.030 & -.087 & $-.128 *$ & -.013 \\
\hline \multicolumn{6}{|l|}{ Importance of motivation for dual screening the debate } \\
\hline Acquiring information & .076 & $.098 *$ & .015 & .134 & $.372 * * *$ \\
\hline Sharing information and opinions & $.175^{* * *}$ & $.117^{*}$ & -.072 & -.128 & $.133^{* *}$ \\
\hline Influencing others & $.162 * * *$ & $.190 * * *$ & $.242 * * *$ & $.268 * * *$ & $.115^{* * *}$ \\
\hline \multicolumn{6}{|l|}{ Specific dual screening practices } \\
\hline Watched the debate live & .284 & .207 & -.002 & .322 & .186 \\
\hline Tuned in after reading about the debate on social media & .186 & $.280 *$ & $.455^{*}$ & $.428 *$ & $.356^{* *}$ \\
\hline Read about the debate on social media & -.054 & -.022 & .278 & .192 & .145 \\
\hline Commented on the debate on social media & $.179 *$ & $.231 * *$ & -.016 & .001 & -.018 \\
\hline \multicolumn{6}{|l|}{ Encountering debate information on Twitter } \\
\hline Via posts on timeline & .109 & -.111 & -.182 & -.014 & $.361 *$ \\
\hline Via hashtags (\#) & -.011 & $.306^{*}$ & .339 & $.577 *$ & $.253 *$ \\
\hline Via mentions (@) and Twitter direct messages & $.513^{* * *}$ & $.390 * *$ & .292 & .165 & .044 \\
\hline Via searching tweets & -.138 & -.068 & .090 & -.055 & .022 \\
\hline Constant & $-3.523 * * *$ & $-3.409 * * *$ & $-4.727 * * *$ & $-3.971 * * *$ & $1.698 * *$ \\
\hline$N$ & 1445 & 1451 & 1447 & 1450 & 1422 \\
\hline Nagelkerke $R^{2}$ & .265 & .224 & .116 & .140 & .282 \\
\hline -2 Log-likelihood & 1633.34 & 1689.71 & 966.01 & 913.23 & 3270.84 \\
\hline
\end{tabular}


Table 3: Factors Predicting Post-Debate Engagement Activities (Poisson regression, Wave 1), Attention to the Campaign (Ordinal Logistic Regression, Waves 1-2) and Having Learned Enough from the Campaign (Logistic Regression, Waves 1-2)

\begin{tabular}{|c|c|c|c|}
\hline & $\begin{array}{c}\text { 1. Post-debate } \\
\text { engagement (Wave 1) }\end{array}$ & $\begin{array}{c}\text { 2. Attention to } \\
\text { campaign (Waves 1-2) }\end{array}$ & $\begin{array}{c}\text { 3. Learned enough } \\
\text { from campaign (Waves 1-2) }\end{array}$ \\
\hline Gender (male) & .004 & .090 & .023 \\
\hline Age (years) & $-.008 * * *$ & -.009 & $-.024 * *$ \\
\hline Education (age of completion) & -.006 & -.196 & $-.364^{* *}$ \\
\hline Income (monthly household before tax) & -.005 & -.017 & .019 \\
\hline Interest in politics & .066 & $1.577 * * *$ & -.093 \\
\hline Internal political efficacy & -.003 & -.050 & .078 \\
\hline Identifying with a party & $.182 *$ & -.130 & .181 \\
\hline Attention to the campaign & .012 & $1.931 * * *$ & -.051 \\
\hline Learning enough from the campaign & .064 & .418 & $1.848 * * *$ \\
\hline Index of political news use & -.007 & .024 & .042 \\
\hline Index of offline political engagement & $.009^{* * *}$ & .017 & .005 \\
\hline Index of online political engagement & $.006 * * *$ & -.006 & .008 \\
\hline Frequency of access to Twitter & -.034 & $.421^{*}$ & .294 \\
\hline Frequency of access to other social media & -.013 & $-.186^{*}$ & -.116 \\
\hline \multicolumn{4}{|l|}{ Importance of motivation for dual screening the debate } \\
\hline Acquiring information & $.046 *$ & -.089 & .005 \\
\hline Sharing information and opinions & .010 & -.045 & -.108 \\
\hline Influencing others & -.022 & .064 & .031 \\
\hline \multicolumn{4}{|l|}{ Specific dual screening practices } \\
\hline Watched the debate live & -.019 & .574 & -.190 \\
\hline Tuned in after reading about the debate on social media & .011 & .143 & -.485 \\
\hline Read about the debate on social media & $.139 * *$ & .243 & .100 \\
\hline Commented on the debate on social media & $.146^{* * *}$ & $.301 *$ & $.325^{*}$ \\
\hline \multicolumn{4}{|l|}{ Encountering debate information on Twitter } \\
\hline Via posts on timeline & .110 & .165 & .591 \\
\hline Via hashtags (\#) & $.198^{* * *}$ & -.053 & .062 \\
\hline Via mentions (@) and Twitter direct messages & $.092 *$ & .070 & -.290 \\
\hline Via searching tweets & $.351^{* * *}$ & .251 & -.101 \\
\hline
\end{tabular}




\section{Outcomes of dual screening}

Influence on others

Assistance with voting decision

$.113^{*}$

$.170 * * *$

$-1.520 * * *$

1342

655.11

Chi Square

3974.82

\section{$-.106$}

$-.130$

.125

$-.035$

-2 Log-likelihood
$5.671^{* * *}$

730

374.31

581.26
$-.436$

719

128.44

526.39

Note: cell entries are unstandardized slope coefficients for the independent variables. When Attention to the campaign is the dependent variable, the independent variable for Attention to the campaign was measured at wave 1 . When Learned enough from the campaign is the dependent variable, the independent variable for Learned enough from the campaign was measured at wave $1 . * * * \mathrm{p} \leq .001 * * \mathrm{p} \leq .01 * \mathrm{p} \leq .05$ 